\title{
Perbedaan arus puncak ekspirasi antara anak asma dengan obesitas dan anak asma tanpa obesitas
}

The difference of peak flow rate between obese asthmatic children and non obese asthmatic children

\author{
Nurul Hadi, ${ }^{1}$ Madarina Julia ${ }^{1}$, Roni Naning ${ }^{1}$
}

\begin{abstract}
Background: Obesity in children is associated with impairment of pulmonary function and increased risk of asthma. Obesity in asthmatic children may reduce lung function, that can be assessed by peak flow meter, a practical and an inexpensive tool. Objectives: To compare the peak expiratory flow (PEF) between obese and non-obese asthmatic children. Method: We conducted a cross sectional study in Yogyakarta during March 2010-September 2012. Fifty obese asthmatic patients and 50 non obese asthmatic control subjects participated in this study. Inclusion criteria were asthmatic patient, according to Pedoman Nasional Asma Anak (PNAA), and 6-18 years of age. Exclusion criteria were asthmatic attack, respiratory disease, heart disease and congenital chest malformation. Obesity is defined as body mass index (BMI) for age more than +3 SD WHO growth chart standards BMI for age 2007 z-score. Z-score is calculated with WHO AnthroPlus for Personal Computers. Data PEF is taken with electrical peak flow meter when the patient was not suffering from asthma attack. Normal PEF was defined as PEF $\geq 80 \%$ average (predicted) value for height. Results: The mean of age of asthmatic children in this study was 9.38 years and 9.50 years for non obese and obese respectively. The PFR was not different between obese asthmatic children and non obese asthmatic children $(p=0,83)$. Pearson correlation of PFR and $z$-score $B M I$ for age was positive weak correlation $(r=0.12)$. There was significant difference of PFR between $z$-score BMI for age $<3,20$ and $z$-score BMI for age $\geq 3.20$ ( $p=0.03$ ). Significant difference of PFR also appears in duration of illness $(p<0.001)$. Conclusion: There is no PFR difference between obese asthmatic children and non-obese asthmatic children. The difference of PFR emerges when statistic analysis performed using $z$-score $B M I \geq 3.20$.
\end{abstract}

KEY WORDS: peak flow rate, obesity, asthma, children

\begin{abstract}
ABSTRAK
Latar belakang: Obesitas pada anak dihubungkan dengan penurunan fungsi paru dan risiko terjadinya asma. Fungsi paru akan mengalami penurunan pada anak asma dengan obesitas. Arus puncak ekspirasi (APE) adalah salah satu parameter yang sering digunakan pada uji fungsi paru karena praktis dan sederhana. Tujuan: Mengetahui perbedaan APE pada anak asma dengan obesitas dan anak asma tanpa obesitas. Metode: Studi cross sectional dilakukan di Yogyakarta dan sekitarnya sejak Maret 2010-September 2012. Subjek penelitian sebanyak 50 anak asma dengan obesitas dan 50 anak asma tanpa obesitas. Kriteria inklusi yaitu semua pasien asma berusia 6-18 tahun dan orang tua menyetujui prosedur penelitian. Kriteria eksklusi adalah anak dalam serangan asma, menderita penyakit pernapasan, penyakit jantung, dan kelainan bawaan bentuk dada. Indeks massa tubuh (IMT) dihitung dari berat badan $(\mathrm{kg})$ dibagi kuadrat tinggi badan $\left(\mathrm{m}^{2}\right)$ kemudian diplot ke dalam WHO growth chart standards BMI for age 2007 -score sesuai jenis kelamin. IMT per umur (IMT/U) dikategorikan obesitas jika terletak di atas +3 standar deviasi (SD). Z-score dihitung menggunakan WHO anthroplus for personal computers. APE diukur dengan peakflow meter electric dan dikategorikan normal jika APE $\geq 80 \%$ nilai rata-rata perkiraan. Hasil: Rerata umur anak asma yang obes dan tidak obes pada penelitian ini adalah 9,50 tahun dan 9,38 tahun. APE tidak berbeda bermakna antara pasien dengan obesitas dan pasien tidak obesitas $(p=0,83)$. Analisis korelasi dengan Pearson menunjukan korelasi yang lemah antara APE dan $z$-score IMT/U $(\mathrm{r}=0,12)$. Namun, terdapat perbedaan bermakna antara APE anak asma dengan $z$-score IMT/U $<3,20$ dan anak asma dengan $z$-score IMT/U $\geq 3,20$ (p=0,03). Perbedaan bermakna pada APE juga tampak pada lamanya sakit asma $(\mathrm{p}<0,001)$. Simpulan: Tidak ada perbedaan APE antara pasien asma dengan obesitas dan pasien asma tanpa obesitas. Perbedaan APE tampak antara $z$-score IMT/U $<3,2$ dengan $z$-score IMT/U $\geq 3,20$.
\end{abstract}

KATA KUNCI: arus puncak ekspirasi, obesitas, asma, anak

\section{PENDAHULUAN}

Prevalensi obesitas pada anak cenderung meningkat, baik di negara maju maupun di negara berkembang (1). Obesitas pada anak berhubungan dengan abnormalitas fungsi pernapasan, meningkatkan stres pernapasan selama latihan fisik, dan dapat menimbulkan gangguan fungsi paru (2). Hasil penelitian di Australia melaporkan peningkatan

\footnotetext{
Korespondensi: Bagian Ilmu Kesehatan Anak, Fakultas Kedokteran Universitas Gajah Mada Yogyakarta, Jl. Farmako, Sekip Utara, Yogyakarta 55281, e-mail: hadinurulita@gamil.com, hadmiz.luth@yahoo.com
} 
risiko terjadinya asma pada obesitas (3). Penurunan hasil fungsi paru pada anak dengan obesitas juga dilaporkan pada penelitian di Colorado (4). Demikian juga hasil penelitian di Korea yang menunjukkan adanya perubahan fungsi paru pada anak perempuan dengan obesitas (5).

Perbedaan yang bermakna secara statistik terjadi pada penurunan arus puncak ekspirasi (APE) sebelum dan sesudah latihan fisik pada kelompok anak obesitas (6). Adanya obesitas dihubungkan dengan penurunan APE $(7,8)$. Arus puncak ekspirasi atau peak flow-rate (PFR) adalah salah satu parameter yang sering digunakan pada uji fungsi paru (9). Korelasi antara hasil pengukuran APE dan nilai force expiratory volume (FEV1) sangat tinggi tetapi perlu dikoreksi terhadap tinggi badan dan umur (10). APE sangat bermanfaat untuk manajemen asma pada anak dan merefleksikan perubahan akut pada jalan napas (9). Anak asma dengan obesitas mempunyai diameter dada yang lebih besar dibandingkan anak tanpa obesitas karena timbunan lemak pada dinding dada sehingga mengurangi daya regang paru. Oleh karena itu, tujuan penelitian ini adalah untuk mengetahui bahwa APE anak asma yang obesitas lebih rendah dibandingkan APE anak asma tanpa obesitas. Dengan diketahui perbedaan APE antara anak asma yang obesitas dengan anak asma tanpa obesitas, diharapkan dapat digunakan sebagai pencegahan dalam penatalaksanaan pasien asma.

\section{BAHAN DAN METODE}

Jenis penelitian ini merupakan penelitian cross sectional yang dilaksanakan sejak bulan Maret 2010 sampai dengan bulan September 2012. Subjek penelitian diambil dari pasien asma yang berkunjung ke Rumah Sakit Umum Pusat (RSUP) Dr. Sardjito Yogyakarta dan pasien terdiagnosis asma yang tinggal di wilayah kerja 15 puskesmas yaitu Puskesmas Tegalrejo dan Puskesmas Kotagede II Kota Yogyakarta; Puskesmas Ngaglik I, Puskesmas Prambanan, dan Puskesmas Depok Kabupaten Sleman; Puskesmas Sedayu I Kabupaten Bantul; Puskesmas Bayan, Puskesmas Bruno, Puskesmas Semawung Daleman, Puskesmas Kutoarjo, Puskesmas Banyuurip, Puskesmas Winong, Puskesmas Wirun, Puskesmas Gebang, dan Puskesmas Kemiri Kabupaten Purworejo. Pemilihan subjek penelitian dengan consecutive sampling.
Kriteria inklusi yaitu semua pasien asma sesuai Pedoman Nasional Asma Anak (PNAA) 2003 (11) yang berusia 6-18 tahun dan orang tua menyetujui prosedur penelitian. Kriteria eksklusi adalah subjek dalam serangan asma yang ditandai dengan adanya mengi dan keluhan sesak napas; menderita penyakit pernapasan seperti tuberkulosis, influenza, faringitis, tonsillitis, pneumonia, dan infeksi saluran napas akut lainnya; menderita penyakit jantung seperti atrial septal defect (ASD), ventricular septal defect (VSD), tetralogy of fallot (TOF), aortic insufficiency (AI), aortic stenosis (AS), mitral insufficiency (MI), mitral stenosis (MS), tricuspid insufficiency (TI), dan patent ductus arteriosus (PDA); serta mempunyai kelainan bawaan pada dada seperti lordosis, kifosis, skoliosis, barrel chest, dan pigeon chest.

Indeks massa tubuh (IMT) dihitung dari berat badan dalam kilogram $(\mathrm{kg})$ dibagi kuadrat tinggi badan dalam meter $\left(\mathrm{m}^{2}\right)$ kemudian diplot ke dalam WHO growth chart standart BMI for age $2007 \mathrm{z}$-score sesuai jenis kelamin. IMT menurut umur (IMT/U) dikategorikan obesitas jika terletak di atas +3 standar deviasi (SD). $Z$-score IMT dihitung dengan komputer menggunakan anthropometric calculator (12).

Arus puncak ekspirasi diukur dengan peak flow meter elektrik Vitalograph, hasil dicocokkan dengan tabel nilai rata-rata APE menurut tinggi badan. Arus puncak ekspirasi dikategorikan normal jika lebih dari atau sama dengan $80 \%$ nilai rata-rata perkiraan dan tidak normal jika kurang dari $80 \%$ nilai rata-rata perkiraan tabel nilai APE (13). Besar sampel dihitung berdasarkan rumus dengan kesalahan tipe I sebesar 5\% untuk hipotesis dua $\operatorname{arah}(\mathrm{Z} \alpha=1,96)$, kesalahan tipe II ditetapkan sebesar $20 \%$ $(\mathrm{Z} \beta=0,84)$, proporsi pada anak asma dengan obesitas yang mempunyai nilai APE tidak normal diperoleh dari penelitian sebelumnya $\left(\mathrm{p}_{2}\right)$ sebesar 0,57 , perbedaan minimal proporsi antara subjek dengan faktor risiko(+), efek(+) dengan faktor risiko(-), efek(+) ditetapkan sebesar $20 \%$ sehingga nilai $p_{1}(0,57-0,2=0,37)$ sebesar 0,37 . Berdasarkan rumus tersebut maka dibutuhkan sampel minimal sebesar 50 pasien untuk masing-masing kelompok.

Pengambilan data meliputi pengisian kuisioner, pengukuran berat badan, tinggi badan, dan APE, serta 
data perokok pada anggota keluarga. Cara melakukan uji fungsi paru dengan peak flow meter yaitu pasien dalam posisi berdiri kemudian masukan mouthpiece sekali pakai ke dalam mulut dan bibir mengatup dengan rapat sehingga tidak ada udara napas keluar di sela-sela bibir, ambil napas dalam dan tahan beberapa detik, hembuskan napas dengan kuat dan cepat, lihat angka yang dicapai pada alat peak flow meter dan dicatat sebagai hasil APE. Pengukuran tersebut dilakukan 3 kali dan hasil yang digunakan adalah hasil APE yang paling tinggi. Pengukuran dilakukan oleh 3 orang terdiri dari 2 orang dokter dan 1 orang sarjana pendidikan.

Semua pasien menjalani penilaian ulang untuk diagnosis asma sesuai dengan PNAA. Wawancara, pengisian kuisioner, dan pengukuran dilakukan di Poliklinik Respirologi Anak RSUP Dr. Sardjito dan di rumah pasien dengan kunjungan rumah bagi pasien yang tidak tercatat sebagai pasien RSUP Dr. Sardjito. Alat ukur berupa timbangan berat badan digital merk Camry dengan kapasitas $150 \mathrm{~kg}$ dan ketelitian 100 gram. Pengukur tinggi badan menggunakan microtoise dengan kapasitas ukur 2 meter dan ketelitian $0,1 \mathrm{~cm}$. Alat yang dipakai untuk pemeriksaan pasien di RSUP Dr. Sardjito sama dengan yang dipakai saat kunjungan rumah.

Analisis statistik menggunakan program komputer SPSS versi 16. Data variabel berskala numerik ditampilkan dalam rerata dan standar deviasi (SD) sedangkan untuk variabel berskala kategorik ditampilkan dalam jumlah (n) dan persentase (\%). Nilai p diperoleh dengan uji $t$ tidak berpasangan untuk variabel berskala numerik sedangkan uji Chi-Square digunakan untuk variabel berskala kategorik. Apabila tidak memenuhi syarat uji $\mathrm{t}$ maka dipakai uji alternatif Mann-Whitney sedangkan alternatif uji mutlak Fisher digunakan apabila tidak memenuhi syarat uji Chi-Square. Nilai p kurang dari 0,05 menunjukan hasil perbedaan yang bermakna antara kelompok obes dan tidak obes. Analisis juga menghitung rasio prevalensi (RP) untuk variabel berskala kategorik dan beda rerata untuk variabel numerik dengan interval kepercayaan $95 \%$.

\section{HASIL}

Hasil penelitian menunjukan bahwa karakteristik data subjek penelitian tidak berbeda bermakna antara kelompok anak asma dengan obesitas dan anak asma tanpa obesitas. Sebagian besar orang tua baik pada kelompok obes maupun tidak obes menyatakan bahwa tidak merokok (74,0\% dan 63,3\%) (Tabel 1).

Adanya obesitas pada anak asma tidak menunjukan perbedaan bermakna dalam hasil APE (Tabel 2). Hasil ini sesuai dengan penelitian di Italia dan New York yang menyatakan bahwa tidak ada perbedaan pada FEV1 pada asma dengan obesitas dan tanpa obesitas $(14,15)$. Namun, berbeda dengan penelitian di Kanada yang melaporkan bahwa obesitas yang menyertai asma mempunyai fungsi paru yang lebih rendah daripada pasien asma tanpa obesitas (16). Perbedaan ini mungkin karena penelitian di Kanada tersebut melibatkan pasien anak dan dewasa. Tipe obesitas pada anak dan dewasa berbeda karena pada anak lebih sering campuran sentral dan perifer sedangkan pada dewasa lebih sering terjadi obesitas sentral yang bisa menurunkan fungsi pernapasan (17-19).

Tabel 1. Karakteristik subjek penelitian

\begin{tabular}{lcc}
\hline \multirow{2}{*}{\multicolumn{1}{c}{ Variabel }} & \multicolumn{2}{c}{ Rerata (SD) } \\
\cline { 2 - 3 } & Tidak obes & Obes \\
\hline Umur (tahun) & $9,38(2,56)$ & $9,50(2,64)$ \\
TB/U (z-score) & $-0,40(1,15)$ & $-0,15(1,19)$ \\
Lama sakit (tahun) & $4,26(2,85)$ & $5,22(2,22)$ \\
\hline
\end{tabular}

Keterangan: Obes $=z$-score $\mathrm{IMT} / \mathrm{U}>3,00$;

$\mathrm{TB} / \mathrm{U}=$ tinggi badan terhadap umur

Tabel 2. Perbedaan APE antara pasien obesitas dan tidak obesitas

\begin{tabular}{|c|c|c|c|c|c|}
\hline & \multicolumn{2}{|c|}{$\operatorname{APE}(n, \%)$} & \multirow{2}{*}{ Total } & \multirow{2}{*}{$\begin{array}{c}\text { RP } \\
\text { (IK 95\%) }\end{array}$} & \multirow{2}{*}{ p } \\
\hline & Tidak normal & Normal & & & \\
\hline Obes & $32(64)$ & $18(36)$ & 50 & 0,92 & 0,83 \\
\hline Tidak obes & $33(66)$ & $17(34)$ & 50 & $(0,40-2,08)$ & \\
\hline Total & 65 & 35 & 100 & & \\
\hline
\end{tabular}

Keterangan: $\mathrm{APE}=$ arus puncak ekspirasi; Obes $=z$-score $\mathrm{IMT} / \mathrm{U}>3,00 ; \mathrm{RP}=$ rasio prevalensi; IK $95 \%$ = interval kepercayaan $95 \%$; Uji Chi-Square $(\mathrm{p}<0,05)$ 
Nurul Hadi, dkk: Perbedaan arus puncak ekspirasi antara anak asma dengan obesitas dan anak asma tanpa obesitas

Tabel 3. Analisis bivariat semua variabel terhadap hasil APE

\begin{tabular}{|c|c|c|c|c|c|c|c|c|}
\hline \multirow{2}{*}{ Variabel } & \multicolumn{2}{|c|}{ APE normal } & \multicolumn{2}{|c|}{ APE tidak normal } & \multirow{2}{*}{$\mathbf{R P}$} & \multirow{2}{*}{$\begin{array}{c}\text { Beda } \\
\text { rerata }\end{array}$} & \multirow{2}{*}{ IK 95\% } & \multirow{2}{*}{$\mathbf{p}$} \\
\hline & n (\%) & Rerata (SD) & n (\%) & Rerata (SD) & & & & \\
\hline Jenis kelamin* & & & & & 2,37 & & $0,94-5,73$ & 0,63 \\
\hline Laki-laki & $26(74,2)$ & & $36(55,4)$ & & & & & \\
\hline Perempuan & $9(25,8)$ & & $29(44,6)$ & & & & & \\
\hline Orang tua merokok* & & & & & 1,89 & & $0,74-4,84$ & 0,18 \\
\hline Ya & $8(22,8)$ & & $23(37,5)$ & & & & & \\
\hline Tidak & $27(77,2)$ & & $41(62,5)$ & & & & & \\
\hline Umur (tahun) $)^{\#}$ & & $9,69(2,61)$ & & $9,31(2,58)$ & & 0,37 & $-0,70-1,45$ & 0,48 \\
\hline TB/U (z-score $)^{\#}$ & & $-0,45(1,10)$ & & $-0,18(1,21)$ & & 0,26 & $-0,75-0,22$ & 0,29 \\
\hline IMT/U (z-score $)^{\#}$ & & $1,79(1,61)$ & & $2,09(1,78)$ & & $-0,29$ & $-1,01-0,42$ & 0,41 \\
\hline Lama sakit (tahun) & & $3,17(2,41)$ & & $5,58(2,24)$ & & $-2,41$ & $-3,77-(-1,45)$ & $<0,001$ \\
\hline
\end{tabular}

Keterangan: * = uji Chi-Square, \# = uji t tidak berpasangan; RP = rasio prevalensi; IK 95\% = interval kepercayaan 95\%; $\mathrm{IMT} / \mathrm{U}=$ indeks massa tubuh menurut umur; $\mathrm{TB} / \mathrm{U}=$ tinggi badan menurut umur

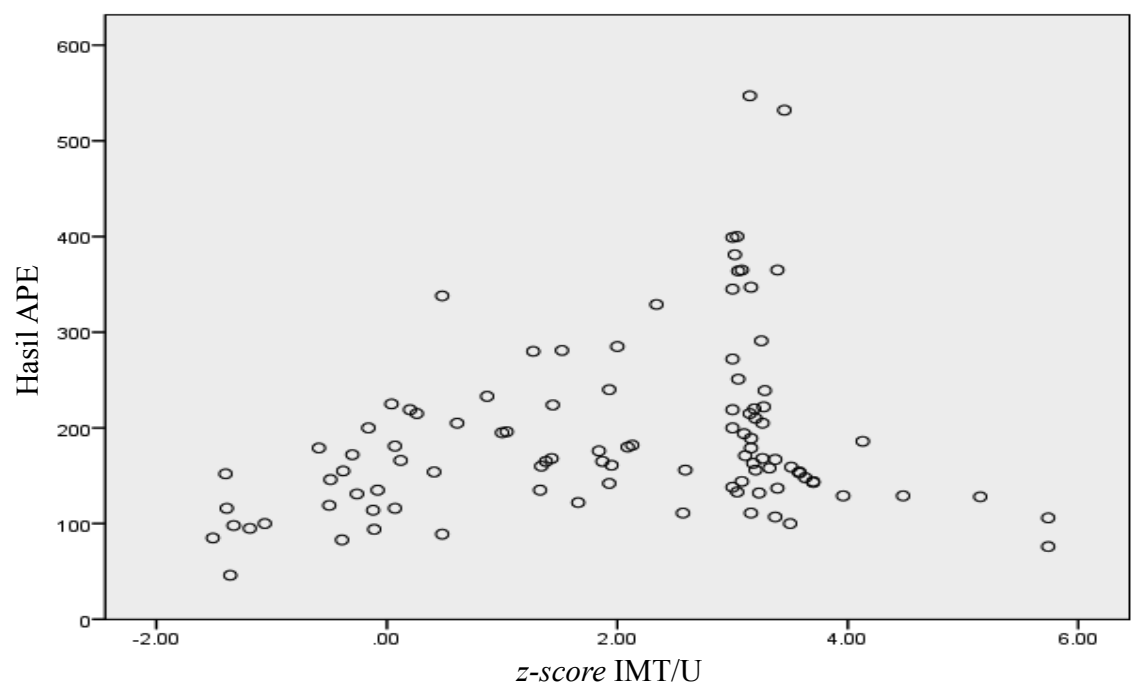

Gambar 1. Scatter plot z-score IMT/umur dengan APE

Usia anak tidak berbeda bermakna pada hasil APE. Hal ini menunjukkan bahwa normal APE tidak dipengaruhi usia tetapi dipengaruhi oleh usia awitan asma dan lamanya sakit asma $(20,21)$. Pada penelitian ini lama sakit asma menunjukan perbedaan bermakna pada hasil APE (Tabel 3). Sebaran hasil $z$-score IMT/U dengan hasil APE disajikan dalam scatter plot. Scatter plot menunjukan kesan bahwa hasil APE meningkat dengan meningkatnya IMT sampai batas tertentu (Gambar. 1).

\section{BAHASAN}

Hasil penelitian menunjukkan tidak adanya perbedaan bermakna hasil APE antara anak yang mempunyai atau tidak anggota keluarga yang merokok. Hasil ini senada dengan penelitian di Los Angeles yang menyatakan bahwa pasien asma yang obes dan tidak obes tidak berbeda dalam hal ada tidaknya anggota keluarga yang merokok (21). Meskipun demikian, perokok pasif berefek pada fungsi paru anak demikian juga usia dewasa baik perokok pasif maupun aktif (22).

Korelasi antara IMT/U (z-score) dengan hasil APE diketahui dengan melakukan analisis Pearson correlation. Hasil uji korelasi didapatkan koefisien korelasi (r) sebesar 0,12 . Korelasi antara IMT/U (z-score) dengan hasil APE menunjukan korelasi positif tetapi sangat lemah. Penelitian di Helsinki melaporkan hasil serupa dengan penelitian ini, bahwa peningkatan IMT berhubungan 
dengan peningkatan fungsi paru pada pemeriksaan spirometri dan menyimpulkan bahwa IMT menunjukan hubungan positif dengan APE (23). Hasil sebaliknya diperoleh dari penelitian di Kocaeli, Turki yaitu terdapat korelasi negatif antara IMT dan APE pada anak usia 6-14 tahun, tetapi menggunakan definisi obesitas yang berbeda yaitu jika nilai IMT lebih dari persentil ke-95 (24). Hasil penelitian di Riyadh yang disimpulkan dalam review menyatakan bahwa peningkatan IMT berhubungan dengan penurunan FEV1 (25). Penelitian di Finlandia juga melaporkan koefisien negatif fungsi paru pada lakilaki dan perempuan dengan peningkatan IMT, meskipun telah disesuaikan dengan usia dan tinggi badan (19). Hubungan negatif yang kuat antara IMT dan APE pada anak juga dilaporkan dari hasil penelitian di Izmir, Turki (26). Namun, penelitian tersebut tidak memisahkan antara pasien asma dan tidak asma.

Sebuah laporan di New York menyatakan bahwa hasil hubungan antara obesitas dan fungsi paru tidak konsisten (27). Hal ini disebabkan oleh perbedaan penggunaan alat pengukur fungsi paru antara peak flow meter oleh sebagian peneliti dan spirometer pada peneliti yang lain. Selain itu, perbedaan hasil mungkin disebabkan oleh banyaknya perbedaan dalam definisi obesitas yaitu sebagian besar berdasarkan berat badan dan tinggi badan daripada menggunakan berat badan total.

Penelitian di Hong Kong menunjukkan bahwa fungsi paru meningkat sesuai dengan peningkatan berat badan dan tinggi badan pada populasi umum anak, tetapi akan mengalami penurunan fungsi paru sesuai dengan meningkatnya persentase lemak tubuh pada berat dan tinggi badan tertentu (28). Peningkatan lean body mass mempunyai efek positif pada fungsi paru, tetapi peningkatan massa lemak berpengaruh sebaliknya. Pada obes ringan, pertambahan berat badan terjadi karena bertambahnya lean body mass dan lemak, berbeda pada obes berat yang pertambahan berat badannya hanya karena peningkatan massa lemak. Penelitian yang dilakukan pada 13 anak dengan obesitas berat (berat badan $=210 \%$ dari rata-rata) menunjukkan penurunan yang bermakna pada fungsi paru (4). Penelitian di Hong Kong yang meneliti pasien asma, menunjukkan penurunan fungsi paru dengan peningkatan massa lemak (28). Efek lemak sangat kecil pada obesitas ringan tetapi sangat besar pada obesitas berat (26).
Batas z-score IMT/U untuk mulai terjadinya penurunan APE diketahui dengan melakukan analisis statistik dengan mengubah batas $z$-score IMT/U menjadi lebih dari atau sama dengan 3,20. Analisis statistik Chi-Square untuk mengetahui perbedaan hasil APE antara $z$-score IMT/U kurang dari 3,20 dengan IMT/U lebih dari atau sama dengan 3,20 menunjukan hasil perbedaan bermakna $(p=0,03)$. Hasil ini membuktikan bahwa perubahan APE tidak terjadi pada obesitas ringan tetapi menurun pada obesitas yang berat. Penelitian di New York menemukan penurunan APE pada anak asma yang obesitas dengan menggunakan definisi obesitas IMT/U lebih dari 85 persentil yang berbeda dengan definisi operasional pada penelitian ini (29). Selain itu, pemeriksaan APE pada penelitian tersebut dilakukan pada saat anak dalam serangan maupun tidak dalam serangan asma sedangkan pada penelitian ini pemeriksaan dilakukan pada saat anak bebas dari serangan asma.

Hasil APE pada penelitian ini menunjukkan tidak adanya perbedaan bermakna antara anak asma yang obesitas dengan anak asma tanpa obesitas. Hal ini terjadi kemungkinan karena APE paling besar dipengaruhi oleh diameter saluran napas yang tidak terpengaruh oleh adanya lemak dalam rongga dada. Penghitungan lean body mass untuk menentukan perbedaan APE pada anak asma mungkin lebih tepat dibandingkan dengan IMT atau berat badan menurut umur. Anak asma yang obesitas dianjurkan untuk mengelola berat badan bukan hanya untuk memperbaiki fungsi paru tetapi mengingat efek buruk obesitas pada kesehatan terutama pada obesitas berat.

\section{SIMPULAN DAN SARAN}

Perbedaan arus puncak ekspirasi terjadi pada obesitas yang lebih berat dengan $z$-score IMT/U lebih dari atau sama dengan 3,20. Perlu penelitian lebih lanjut arus puncak ekspirasi pada anak asma yang mengalami obesitas berat dengan $z$-score IMT/U $\geq 3,20$.

\section{RUJUKAN}

1. Tantisira KG, Litonjua AA, Weiss ST, Fuhlbrigge AL. Association of body mass with pulmonary function in the Childhood Asthma Management Program (CAMP). Thorax 2003;58(12):1036-41. 
2. Wulandari L, Edo MLU. Dampak obesitas terhadap fungsi paru. Majalah Farmacia 2007;68.

3. Schachter LM, Salome CM, Peat JK, Woolcock AJ. Obesity is a risk for asthma and wheeze but not airway hyperresponsiveness. Thorax 2001;56(1):4-8.

4. Eisenmann JC, Arnall DA, Kanuho V, Interpretter C, Coast JR. Obesity and pulmonary function in Navajo and Hopi children. Ethn Dis 2007;17(1):14-8.

5. Jeon YH, Yang HJ, Pyun BY. Lung function in Korean adolescent girls: in association with obesity and the menstrual cycle. J Korean Med Sci 2009;24(1):20-5.

6. Siregar FZ. Perbandingan arus puncak ekspirasi sebelum dan sesudah latihan fisik pada anak obesitas dan tidak obesitas [Tesis]. Sumatera: Perpustakaan USU; 2008.

7. Rubenstein I, Zamei N, Dubarry L, Hoffstein V. Airflow limitation in morbidly obese, nonsmoking men. Ann Intern Med 1990;112(11):828-32.

8. Biring MS, Lewis MI, Liu JT. Pulmonary physiological changes of morbid obesity. Am J Med Sci 1999;318(5):293-7.

9. Voter KZ, McBride JT. Back to basics: diagnostic tests of lung function. Pediatrics in Review 1996;17(2):53-63.

10. Wirjodiardjo M, Said M, Boediman HI. Perbandingan hasil pengukuran peak flow rate antara miniwright peak flow meter dan spirometer elektronik pada anak. Maj Kedok Indon 1992;42(10):575-85.

11. UKK Pulmonologi PP IDAI. Pedoman nasional asma anak. Jakarta: UKK Pulmonologi PP IDAI, Indonesian Pediatric Respiratory; 2003.

12. World Health Organization. WHO anthroplus for personal computers manual. [series online] 2009 [cited $2010 \mathrm{Jan}$ ]. Available from: URL: http://www.who.int/childgrowth/ software/en/

13. Polgar G, Promedhat V. Pulmonary function testing in children: techniques and standards. Philadelphia: W.B. Saunders; 1971.

14. Consilvio NP, Di Pillo S, Verini M, de Giorgis M, Cingolani A, Chiavaroli V, Chiarelli F, Mohn A. The reciprocal influences of asthma and obesity on lung function testing, AHR and airway inflammation in prepubertal children. Pediatr Pulmonol 2010;45(11):1103-10.

15. Rastogi D, Canfield SM, Andrade A, Isasi CR, Hall CB, Rubinstein A, Arens R. Obesity-associated asthma in children: a distinct entity. Chest 2012;141(4):895-905.

16. Pakhale S, Doucette S, Vandemheen K, Boulet LP, McIvor RA, Fitzgerald JM, Hernandez P, Lemiere C, Sharma S, Field SK, Alvarez GG, Dales RE, Aaron SD. A comparison of obese and nonobese people with asthma: exploring an asthma-obesity interaction. Chest 2010;137(6):1316-23.
17. Zhang MX, Zhao XY, Li M, Cheng H, Hou DQ, Wen Y, Katherine C, Mi J. Abnormal adipokines associated with various types of obesity in Chinese children and adolescents. Biomed Environ Sci 2011;24(1):12-21.

18. Wang H, Wang J, Liu M, Wang D, Liu Y, Zhao Y, Huang M, Liu Y, Sun J, Dong H. Epidemiology of general obesity, abdominal obesity and related risk factors in urban adults from 33 communities of northeast china: the CHPSNE study. BMC Public Health 2012;12(967):1-10.

19. Canoy D, Pekkanen J, Elliott P, Pouta A, Laitinen J, Hartikainen AL, Zitting P, Patel S, Little MP, Järvelin MR. Early growth and adult respiratory function in men and women followed from the fetal period to adulthood. Thorax 2007;62(5):396-402.

20. Hellberg J. Factor associated with lung function impairment in children and adults with obstructive lung disease [Thesis]. Stockholm, Sweden: Karolinska Institutet; 2008.

21. Berhane K, McConnell R, Gilliland F, Islam T, Gauderman WJ, Avol E, London SJ, Rappaport E, Margolis HG, Peters JM. Sex-specific effects of asthma on pulmonary function in children. Am J Respir Crit Care Med 2000;162(5):172330.

22. Litof C. Asthma, poor respiratory function in children linked more firmly to parents lifestyles. J Respir Dis 2012;19.

23. Tantisira K, Weiss S. Complex interactions in complex traits: obesity and asthma. Thorax 2001;56(2):64-73.

24. Gundogdu Z, Eryilmaz N. Correlation between peak flow and body mass index in obese and non-obese children in Kocaeli, Turkey. Prim Care Respir J 2011;20(4):403-6.

25. Poulain M, Doucet M, Major GC, Drapeau V, Sériès F, Boulet LP, Tremblay A, Maltais F. The effect of obesity on chronic respiratory diseases: pathophysiology and therapeutic strategies. CMAJ 2006;174(9):1293-9.

26. Ülger Z, Demir E, Tanaç R, Göksen D, Gülen F, Darcan $\mathrm{S}$, Can D, Coker M. The effect of childhood obesity on respiratory function tests and airway hyperresponsiveness. Turk J Pediatr 2006;48(1):43-50.

27. Belamarich PF, Luder E, Kattan M, Mitchell H, Islam S, Lynn H, Crain EF. Do obese inner-city children with asthma have more symptoms than nonobese children with asthma?. Pediatrics 2000;106(6):1436-41.

28. Lazarus R, Sparrow D, Weiss ST. Effect of obesity and fat distribution on ventilation function: the normative aging study. Chest 1997;111(4):891-8.

29. Luder E, Melnik TA, DiMaio M. Association of being overweight with greater asthma symptoms in inner city black and Hispanic children. J Pediatr 1998;132(4):699703. 